\title{
Synthesis and characterization of hollow $\mathrm{V}_{2} \mathrm{O}_{5}$ microspheres for supercapacitor electrode with pseudocapacitance
}

\author{
YIFU ZHANG* \\ School of Chemistry, Dalian University of Technology, Dalian 116024, PR China
}

\begin{abstract}
Hollow $\mathrm{V}_{2} \mathrm{O}_{5}$ microspheres (HVOM) were fabricated using $\mathrm{NH}_{4} \mathrm{VO}_{3}$, ethylene glycol and carbon spheres as the starting materials by a template solvothermal approach and subsequent calcination. The morphology and composition were characterized by field emission scanning electron microscopy (FE-SEM), X-ray powder diffraction (XRD), Fourier transform infrared spectroscopy (FT-IR) and Brunauer-Emmet-Teller (BET). The results showed that the obtained HVOM were constructed from nanoparticles with rough surface. The electrochemical properties of HVOM as a supercapacitor electrode were investigated by cyclic voltammetry (CV) and galvanostatic charge-discharge (GCD). HVOM displayed excellent pseudocapacitance property and their specific capacitances were $488 \mathrm{~F} \cdot \mathrm{g}^{-1}, 455 \mathrm{~F} \cdot \mathrm{g}^{-1}, 434 \mathrm{~F} \cdot \mathrm{g}^{-1}$ and $396 \mathrm{~F} \cdot \mathrm{g}^{-1}$ at the current density of $0.5 \mathrm{~A} \cdot \mathrm{g}^{-1}$, $1 \mathrm{~A} \cdot \mathrm{g}^{-1}, 2 \mathrm{~A} \cdot \mathrm{g}^{-1}$ and $5 \mathrm{~A} \cdot \mathrm{g}^{-1}$, respectively. They also exhibited an excellent energy density of $8.784 \times 10^{5} \mathrm{~J} \cdot \mathrm{kg}^{-1}$ at a power density of $900 \mathrm{~W} \cdot \mathrm{kg}^{-1}$. The good electrochemical properties of the as-synthesized HVOM make them a promising candidate as a cathode material for supercapacitors.
\end{abstract}

Keywords: $\mathrm{V}_{2} \mathrm{O}_{5}$; hollow microspheres; electrical properties; supercapacitor; pseudocapacitance

(C) Wroclaw University of Science and Technology.

\section{Introduction}

Supercapacitors (SCs) bridge the gap between batteries and conventional solid-state and electrolytic capacitors because of their high power density, rapid charging/discharging rate, superior rate capability, long operating lifetimes and low maintenance cost [1-6]. These remarkable properties make SCs to be considered as one of the most promising candidates for the next-generation energy storage devices. The performance of SCs is strongly dependent on the properties of electrode materials. Carbon materials, transition metals oxides, hydroxides, sulfides and conductive polymers are widely used in SCs [2]. Two types of SCs can be distinguished based on the charge storage mechanism: double-layer capacitance (non-faradaic process) with carbon electrodes and pseudocapacitors (faradaic process) with transition metal oxides electrodes and higher specific capacitance than double-layer capacitance $[2,4,7]$.

\footnotetext{
*E-mail: yfzhang@dlut.edu.cn
}

Vanadium oxides and their related compounds have received increasing attention as functional materials owing to their layered structures, novel chemical and physical properties, which make them promising in a wide range of potential applications, such as cathode materials for reversible lithium batteries, catalysts, SCs, intelligent thermochromic windows, electrical and optical devices, laser shields and so on [8-21]. Recently, $\mathrm{V}_{2} \mathrm{O}_{5}$ as one of the promising candidates for electrode materials in SCs has attracted increasing attention because of its low cost, unique layered structure, abundance and high potential pseudocapacitive characteristics $[3,22,23]$. To date, lots of $\mathrm{V}_{2} \mathrm{O}_{5}$ with different structures and morphologies have been synthesized for SCs electrodes [3, 23-28], including microspheres, nanobelts, nanowires, nanoflowers, nanofibers, 3D-architectures, nanoporous networks, nanochains, etc. The performed investigations demonstrated that the performance of $\mathrm{V}_{2} \mathrm{O}_{5}$ SCs is strongly dependent on their morphology and structure. In the past decades, hollow $\mathrm{V}_{2} \mathrm{O}_{5}$ microspheres (HVOM) have attracted great interest 
owing to their excellent applications as cathode materials for Li- and Na-ion batteries [29-32]. For examples, Pan et al. [29] reported HVOM synthesized from $\mathrm{VO}_{2}$ hollow spheres and exhibited a high initial reversible capacity of $256 \mathrm{mAh} \cdot \mathrm{g}^{-1}$ at a current density of $300 \mathrm{mAh} \cdot \mathrm{g}^{-1}$. Su et al. [31] reported HVOM prepared from vanadyl ethylene glycolate (VEG) hollow nanospheres which demonstrated a good high-rate capability and cycling stability. However, HVOM used as the cathode material for SCs has rarely been reported. Yang et al. [22], based on the results obtained by the cyclic voltammetry (CV) method, reported that hollow $\mathrm{V}_{2} \mathrm{O}_{5}$ spheres exhibited the maximum capacitance of $479 \mathrm{~F} \cdot \mathrm{g}^{-1}$ at $5 \mathrm{mV} \cdot \mathrm{s}^{-1}$ when used as $\mathrm{SCs}$ electrodes in $5 \mathrm{M} \mathrm{LiNO}_{3}$.

In this contribution, HVOM were synthesized by a facile solvothermal approach and subsequent calcination, using $\mathrm{NH}_{4} \mathrm{VO}_{3}$, ethylene glycol (EG) and carbon spheres as the starting materials. Furthermore, hollow $\mathrm{V}_{2} \mathrm{O}_{5}$ microspheres, used as SCs electrodes, exhibited an excellent pseudocapacitance.

\section{Experimental}

\subsection{Synthesis of template carbon spheres}

All the chemicals used in the experiments were of analytical grade and were used as received without any further purification. The synthesis of colloidal carbon spheres was based on the previous report [33]. In a typical procedure, $30 \mathrm{~cm}^{3}$ of $1.0 \mathrm{~mol} \cdot \mathrm{dm}^{-3}$ glucose solution was transferred into a $50 \mathrm{~cm}^{3}$ Teflon lined stainless steel autoclave, which was sealed and maintained at $180{ }^{\circ} \mathrm{C}$ for 8 hours. After cooling to room temperature naturally, the products were filtered off, washed with distilled water and absolute ethanol several times, and dried in vacuum at $75^{\circ} \mathrm{C}$.

\subsection{Synthesis of HVOM}

In a typical procedure, $0.585 \mathrm{~g}$ of $\mathrm{NH}_{4} \mathrm{VO}_{3}$ was dispersed in $30 \mathrm{~cm}^{3}$ of ethylene glycol (EG) under vigorous stirring, then some amount of carbon spheres was added. After the mixture was vigorously stirred and ultrasonically treated, it was transferred into a $50 \mathrm{~cm}^{3}$ Teflon lined stainless steel autoclave at $180{ }^{\circ} \mathrm{C}$ for 24 hours. The products were filtered off, washed with distilled water and absolute ethanol several times, and dried in vacuum at $75^{\circ} \mathrm{C}$. Finally, the products were heated in a muffle furnace with $5{ }^{\circ} \mathrm{C} / \mathrm{min}$ heating rate at $500{ }^{\circ} \mathrm{C}$ for 2 hours under the air atmosphere.

\subsection{Characterization}

The morphology and dimensions of the products were observed by field emission scanning electron microscopy (FE-SEM, NOVA NanoSEM 450, FEI). The phase and composition of the products was identified by X-ray powder diffraction (XRD, PANalytical X'Pert Powder Diffractometer at $40 \mathrm{kV}$ and $40 \mathrm{~mA}$ with Ni-filtered $\mathrm{CuK} \alpha$ radiation). Infrared spectroscopy (IR) pattern of the solid samples was measured using $\mathrm{KBr}$ pellet technique (about 1 wt.\% of the sample and 99 wt.\% of $\mathrm{KBr}$ were mixed homogeneously, and then the mixture was pressed into a pellet) and recorded on a Nicolet 6700 spectrometer from $4000 \mathrm{~cm}^{-1}$ to $400 \mathrm{~cm}^{-1}$ with a resolution of $4 \mathrm{~cm}^{-1}$. Surface area was determined by Brunauer-Emmet-Teller (BET) method using Micromeritics ASAP-2020 and the samples were degassed at $150{ }^{\circ} \mathrm{C}$ for several hours.

\subsection{Electrochemical characterization}

Electrochemical tests were performed using a three-electrode cell, in which Ni-grid and saturated calomel electrode (SCE) were used as the counter and the reference electrode, respectively. The working electrodes were comprised of $80 \mathrm{wt} . \%$ of active material, $10 \mathrm{wt} . \%$ of carbon black and 10 wt.\% of polyvinylidene difluoride (PVDF). N-methyl-2-pyrrolidone (NMP) was used as a solvent. The mixed slurries were coated onto $\mathrm{Ni}$ foils and heated at $80{ }^{\circ} \mathrm{C}$ overnight to remove the organic solvent. Then these foils were pressed onto Ni-grids at a pressure of $10 \mathrm{MPa}$. The electrolyte was $1 \mathrm{~mol} \cdot \mathrm{dm}^{-3} \mathrm{LiNO}_{3}$ solution. Cyclic voltammetry (CV) and galvanostatic charge-discharge (GCD) were used to obtain the electrochemical characteristics. CV data were collected between $-0.4 \mathrm{~V}$ and $0.6 \mathrm{~V}$ at a scan rate $\left(20 \mathrm{mV} \cdot \mathrm{s}^{-1}\right)$ and GCD tests 

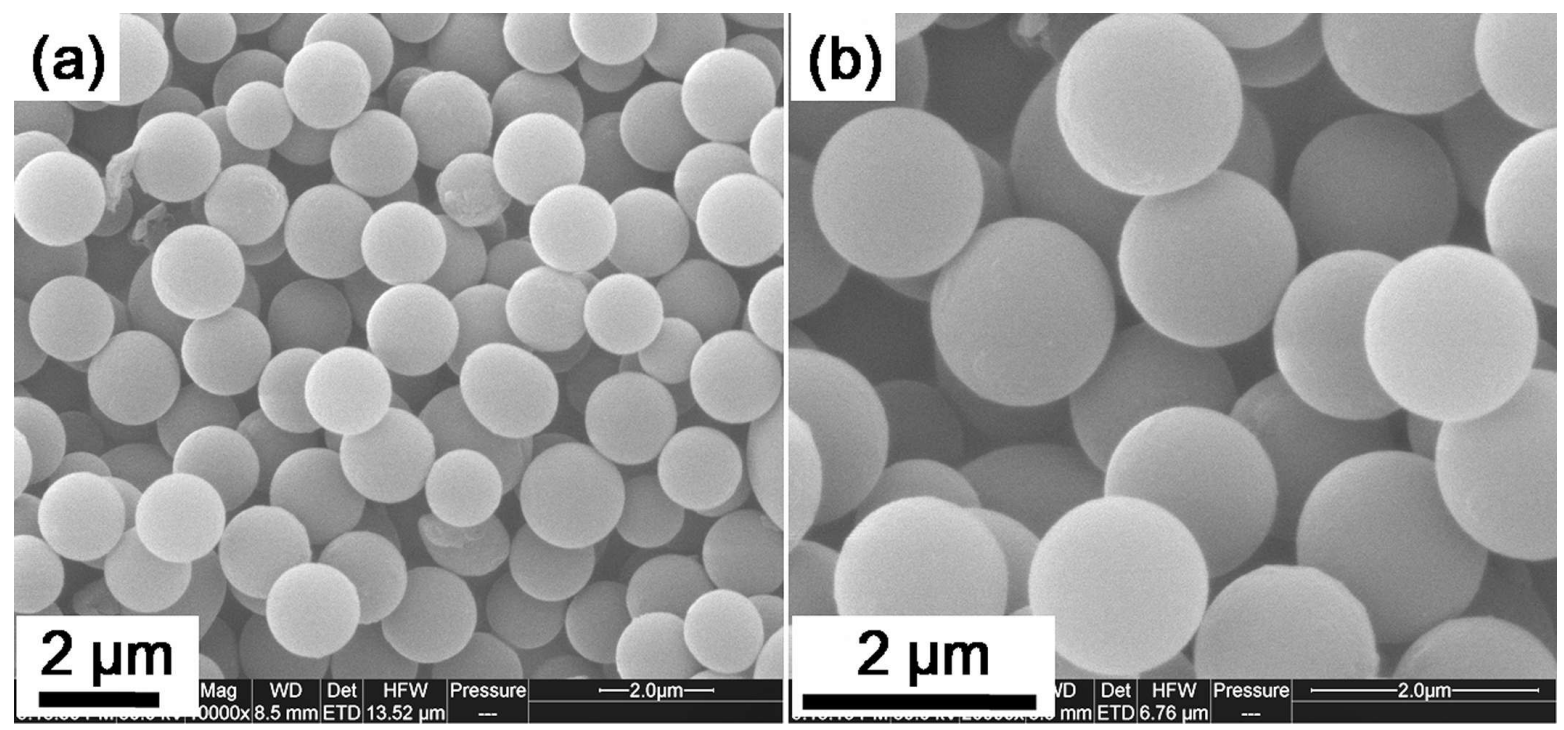

Fig. 1. FE-SEM images of the template carbon spheres.

were performed in the potential range of $-0.4 \mathrm{~V}$ to $0.6 \mathrm{~V}$ at a current density of $0.5 \mathrm{~A} \cdot \mathrm{g}^{-1}$ to $5 \mathrm{~A} \cdot \mathrm{g}^{-1}$.

The specific capacitance $\left(C, F \cdot g^{-1}\right)$ and energy density $\left(\mathrm{E}, \mathrm{J} \cdot \mathrm{kg}^{-1}\right)$ of the active material in the electrode, determined using charge-discharge curves, can be calculated from the following equations:

$$
\begin{gathered}
C=\frac{I \cdot \Delta t}{m \cdot \Delta V} \\
\mathrm{E}=\frac{1}{2} \mathrm{C} \cdot(\Delta \mathrm{V})^{2}
\end{gathered}
$$

where $\mathrm{C}\left(\mathrm{F} \cdot \mathrm{g}^{-1}\right)$ is the specific capacitance, I (A) is the discharge current, $\Delta \mathrm{t}(\mathrm{s})$ is the discharge time, $\mathrm{m}(\mathrm{g})$ is the mass of the active material in the working electrode, $\Delta \mathrm{V}(\mathrm{V})$ represents the potential drop during the discharge process, and $\mathrm{E}\left(\mathrm{J} \cdot \mathrm{kg}^{-1}\right)$ is the energy density. The power density $\mathrm{P}\left(\mathrm{W} \cdot \mathrm{kg}^{-1}\right)$ can be calculated from the energy density $\mathrm{E}$ and the discharge time $\Delta \mathrm{t}$ according to the following equation:

$$
\mathrm{P}=\frac{\mathrm{E}}{\Delta \mathrm{t}}
$$

\section{Results and discussion}

Fig. 1 shows the FE-SEM images of the carbon spheres, which reveal that the uniform carbon spheres are obtained in agreement with the literature [33]. Fig. 2 depicts the FE-SEM images of the prepared sample. The overall view (Fig. 2a and Fig. 2b) show that the sample consists of microspheres with the diameters of $5 \mu \mathrm{m}$ to $6 \mu \mathrm{m}$. From the broken microspheres (Fig. 2c and Fig. 2d), the spheres are hollow structures. The hollow microspheres were constructed from nanoparticles to form rough surfaces and enormous cavities, which would provide promising applications of the material in Li-ion intercalation and extraction [3].

Fig. 3 shows the XRD patterns of the hollow microspheres, which reveal that all the diffraction peaks can be indexed as the orthorhombic crystalline phase (space group: Pmmn 59) of $\mathrm{V}_{2} \mathrm{O}_{5}$ with a lattice constants values of $\mathrm{a}=1.1516 \mathrm{~nm}, \mathrm{~b}=$ $0.35656 \mathrm{~nm}$, and $\mathrm{c}=0.4372 \mathrm{~nm}$ (JCPDS Card No. 41-1426), whose plots are shown in Fig. 3a. No obvious peaks of any other impurities are detected, suggesting that HVOM with a high purity were synthesized.

Fig. 4 depicts IR spectrum of the as-obtained HVOM. The absorption peaks ranging from $1200 \mathrm{~cm}^{-1}$ to $400 \mathrm{~cm}^{-1}$ are assigned to the characteristic $\mathrm{V}-\mathrm{O}$ vibration band $[18,34,35]$. The peak at $1018 \mathrm{~cm}^{-1}$ is attributed to the symmetric stretching vibration of $\mathrm{V}^{5+}=\mathrm{O}$ bond, which 

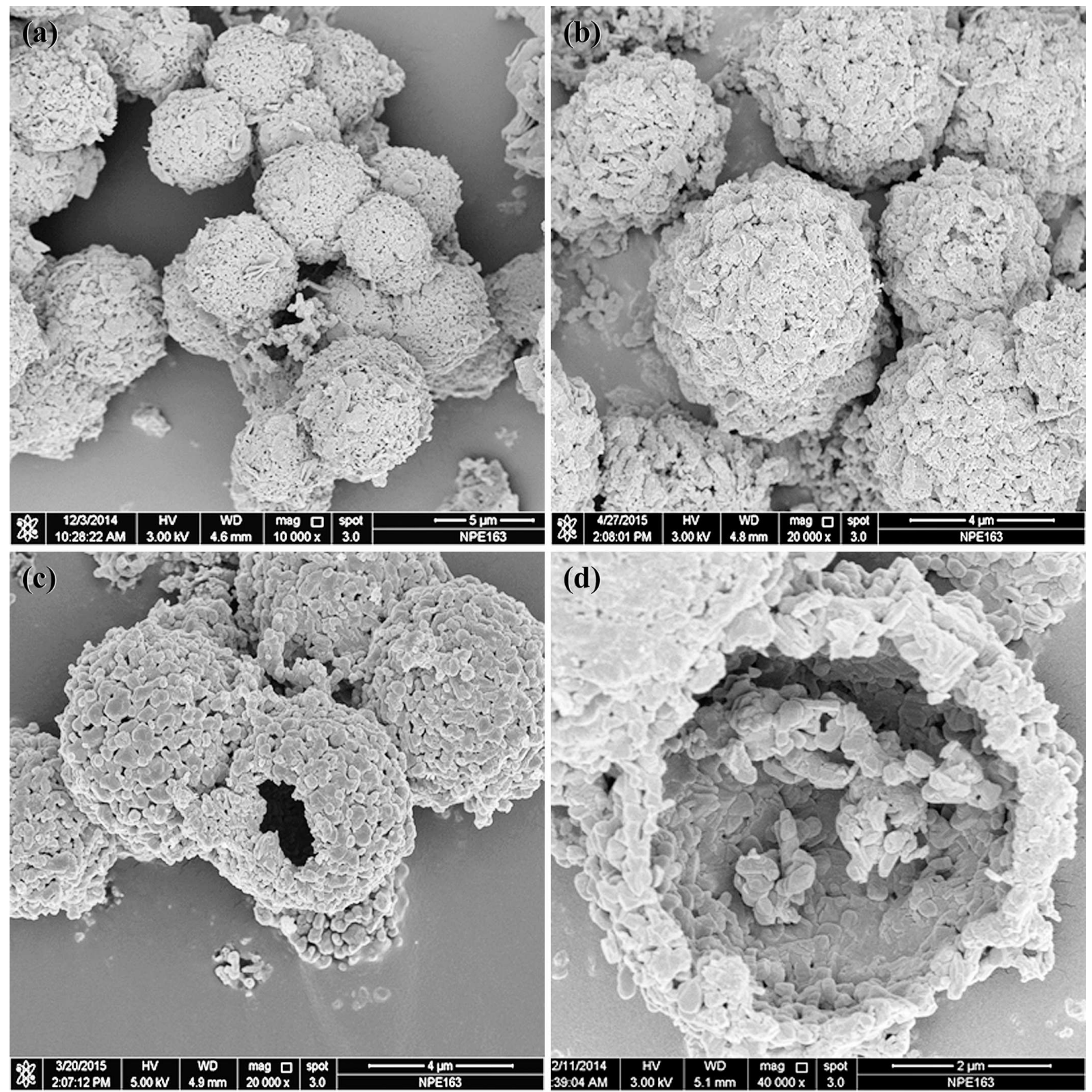

Fig. 2. FE-SEM images of the as-obtained sample.

is the characteristic structure of the layered orthorhombic $\mathrm{V}_{2} \mathrm{O}_{5}$ [35]. The absorption band at $840 \mathrm{~cm}^{-1}$ is assigned to the vibration of $\mathrm{O}-(\mathrm{V})_{3}$. The absorption peaks at 639 and $477 \mathrm{~cm}^{-1}$ correspond to the asymmetric and the symmetric stretching modes of $\mathrm{V}-\mathrm{O}-\mathrm{V}$ bridging bonds. Besides, the absorption peaks at 3439 and $1630 \mathrm{~cm}^{-1}$ are attributed to the stretching modes of water molecules adsorbed on the samples and can be disregarded. The above analysis is in agreement with the result of XRD analysis.

Fig. 5a shows the $\mathrm{N}_{2}$ adsorption-desorption isotherms of the as-obtained HVOM. The isotherms depict a sharp capillary condensation step at high relative pressure, which belongs to type IV isotherm according to IUPAC classification. The specific surface area of HVOM obtained 


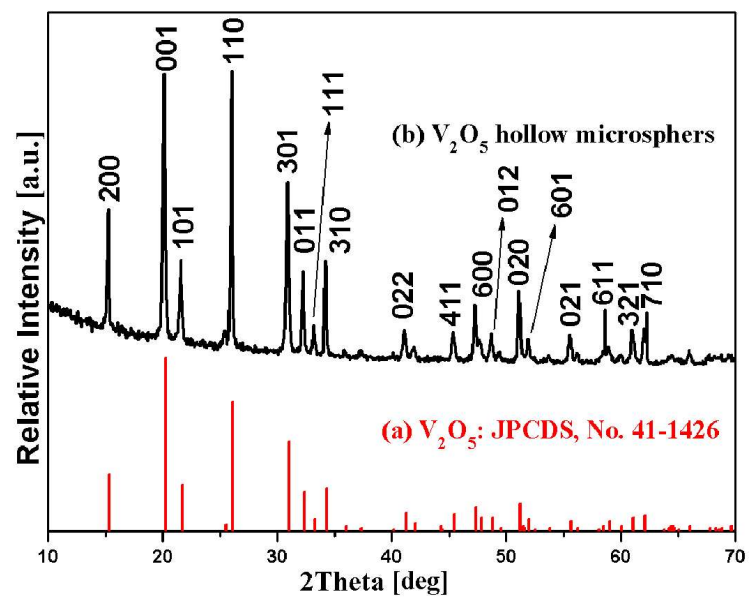

Fig. 3. XRD patterns of the as-obtained hollow microspheres.

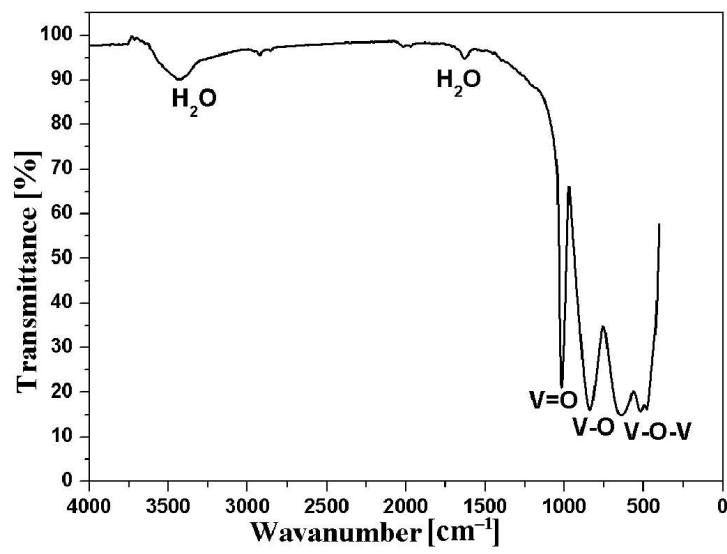

Fig. 4. IR spectrum of the as-obtained HVOM.

by BET method is $7.3 \mathrm{~m}^{2} \cdot \mathrm{g}^{-1}$, as depicted in Fig. 5b.

To exhibit the merits of the as-obtained HVOM, the electrochemical investigation of their pseudocapacitance was evaluated by CV and GCD tests in a three electrode cell. Fig. 6a shows CV curves of $\mathrm{HVOM}$ on various potential limits in $1 \mathrm{~mol} \cdot \mathrm{dm}^{-3}$ $\mathrm{LiNO}_{3}$ electrolyte at a scan rate $20 \mathrm{mV} \cdot \mathrm{s}^{-1}$, which indicate that the electrode in $\mathrm{LiNO}_{3}$ solution has been proven to offer the best reversibility and reactivity in the $-0.4 \mathrm{~V}$ to $0.6 \mathrm{~V}$ range. Fig. $6 \mathrm{~b}$ displays the CV curves of HVOM and foamed $\mathrm{Ni}$. The foamed Ni has no redox peak. HVOM show two pairs of redox peaks: two anodic peaks at $0.025 \mathrm{~V}$ and $0.213 \mathrm{~V}$ at positive current density and two cathodic peaks at $0.056 \mathrm{~V}$ and $-0.112 \mathrm{~V}$ at negative current density. The above peaks are associated with the intercalation/deintercalation of $\mathrm{Li}^{-}$ ion into/from HVOM, indicating that they have pseudocapacitance property $[3,22,36]$. The electrochemical reaction can be expressed as follows:

$$
\mathrm{V}_{2} \mathrm{O}_{5}+x \mathrm{Li}+x e^{-\frac{\text { discharge }}{\text { charge }}} \mathrm{Li}_{x} \mathrm{~V}_{2} \mathrm{O}_{5}(0 \leqslant x \leqslant 1)
$$

The changes of crystal phases which occurred during the whole process were generally designated as $\alpha(0<\mathrm{x}<0.1), \epsilon(0.35<\mathrm{x}<0.5)$ and $\delta(0.9<\mathrm{x}<1)[22,36]$.

To calculate the specific capacitance and understand the rate capability of HVOM, the charge and discharge tests were performed at various current densities (Fig. 7). The specific capacitance of HVOM shown in Fig. 7a, calculated from equation 1 , is $488 \mathrm{~F} \cdot \mathrm{g}^{-1}, 455 \mathrm{~F} \cdot \mathrm{g}^{-1}, 434 \mathrm{~F} \cdot \mathrm{g}^{-1}$ and $396 \mathrm{~F} \cdot \mathrm{g}^{-1}$ at the current density of $0.5 \mathrm{~A} \cdot \mathrm{g}^{-1}$, $1 \mathrm{~A} \cdot \mathrm{g}^{-1}, 2 \mathrm{~A} \cdot \mathrm{g}^{-1}$ and $5 \mathrm{~A} \cdot \mathrm{g}^{-1}$, respectively. The specific capacitance gradually decreases at higher current densities owing to the incremental voltage drop and insufficient active material being involved in the redox reaction at a higher current density $[4,25]$. In addition, the process of chargedischarge at a high current density may lead to a low utilization rate of active material [2]. The SCs performance of HVOM is much higher than the literature reports, as summarized in Table 1. Fig. 7b shows a Ragone plot of HVOM. Based on equation 2 and equation 3 , the calculated $\mathrm{E}$, at the current densities of $0.5 \mathrm{~A} \cdot \mathrm{g}^{-1}, 1 \mathrm{~A} \cdot \mathrm{g}^{-1}, 2 \mathrm{~A} \cdot \mathrm{g}^{-1}$ and $5 \mathrm{~A} \cdot \mathrm{g}^{-1}$ are $8.784 \times 10^{5} \mathrm{~J} \cdot \mathrm{kg}^{-1}, 8.208 \times 10^{5} \mathrm{~J} \cdot \mathrm{kg}^{-1}$, $7.812 \times 10^{5} \mathrm{~J} \cdot \mathrm{kg}^{-1}$ and $7.128 \times 10^{5} \mathrm{~J} \cdot \mathrm{kg}^{-1}$ and the power densities are $900 \mathrm{~W} \cdot \mathrm{kg}^{-1}, 1800 \mathrm{~W} \cdot \mathrm{kg}^{-1}$, $3600 \mathrm{~W} \cdot \mathrm{kg}^{-1}$ and $9000 \mathrm{~W} \cdot \mathrm{kg}^{-1}$, respectively. The above results exhibit the outstanding SCs performance of HVOM.

Cycling stability is a critical parameter for highperformance SCs. The CV and GCD tests were used to observe and quantitatively describe the cycling stability of HVOM. Fig. 8 that shows the CV curves of HVOM at different cycles, intuitively reveals that the specific capacitance quickly fades with the cycles increasing. Fig. 9a exhibits 

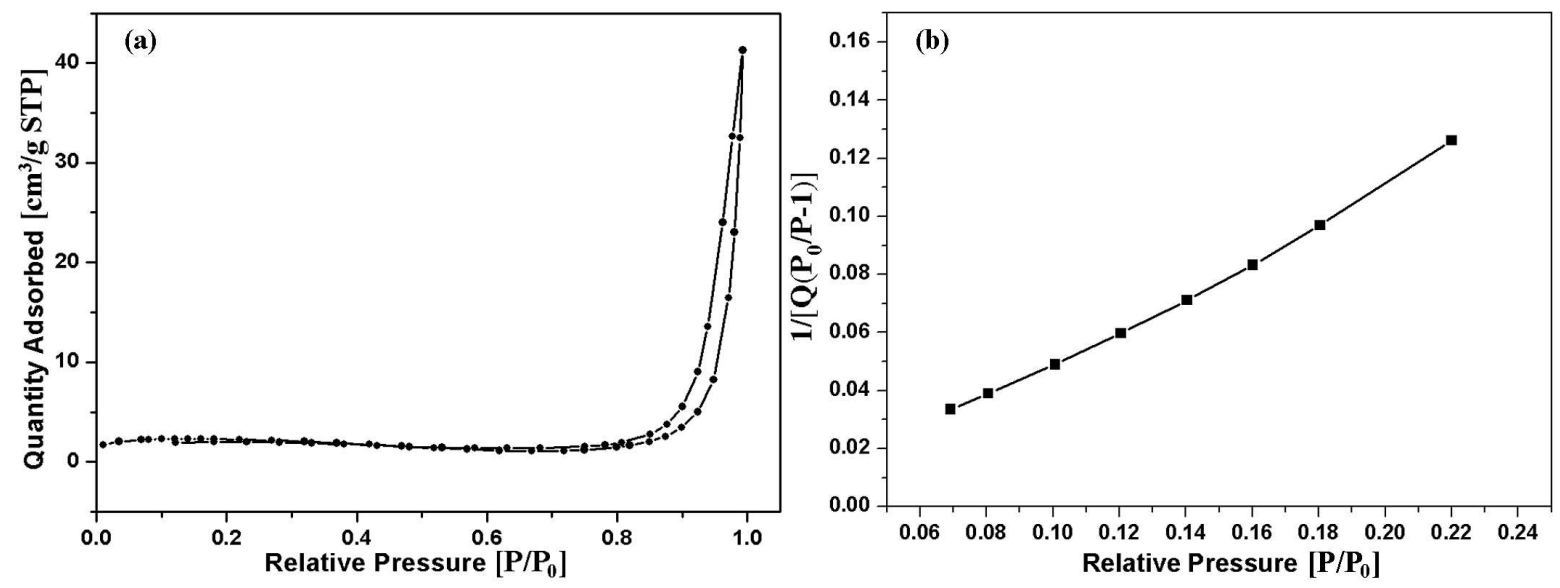

Fig. 5. (a) Nitrogen adsorption-desorption isotherms and (b) BET curve of the as-obtained HVOM.
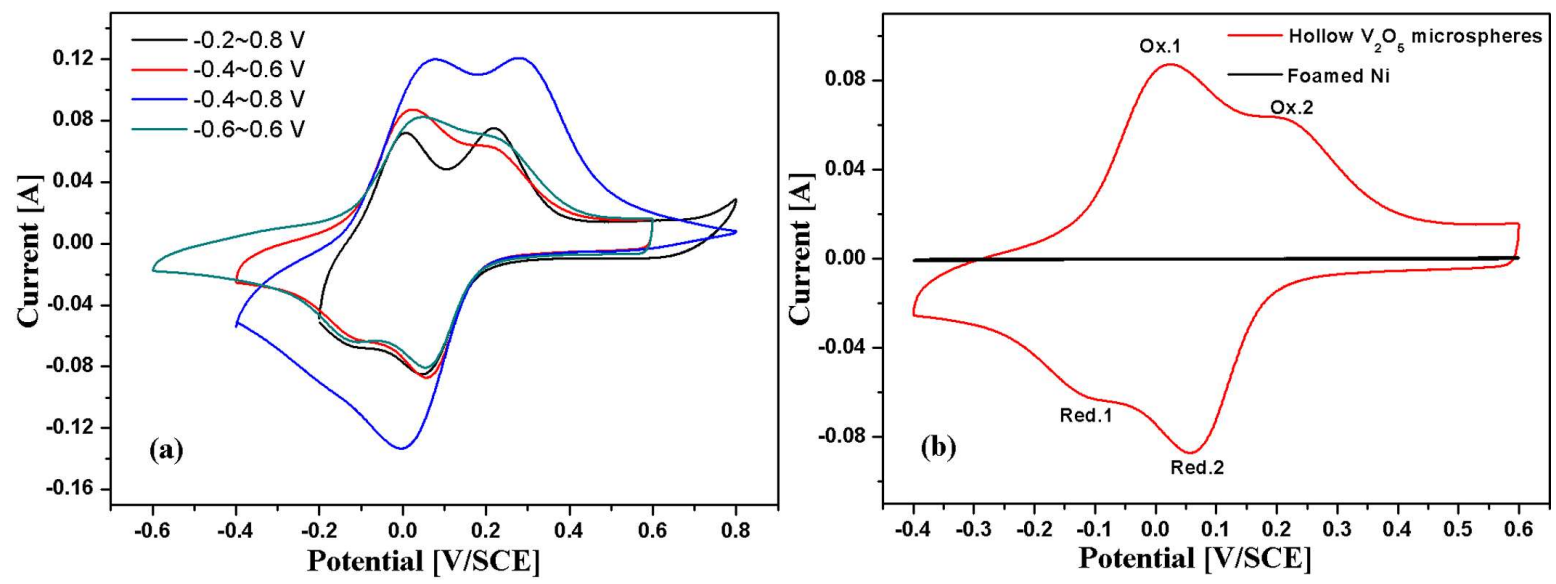

Fig. 6. $\mathrm{CV}$ curves of $\mathrm{HVOM}$ in $1 \mathrm{~mol} \cdot \mathrm{dm}^{-3} \mathrm{LiNO}_{3}$ at a scan rate $20 \mathrm{mV} \cdot \mathrm{s}^{-1}$ : (a) on various potential limits; (b) compared with foamed $\mathrm{Ni}$.
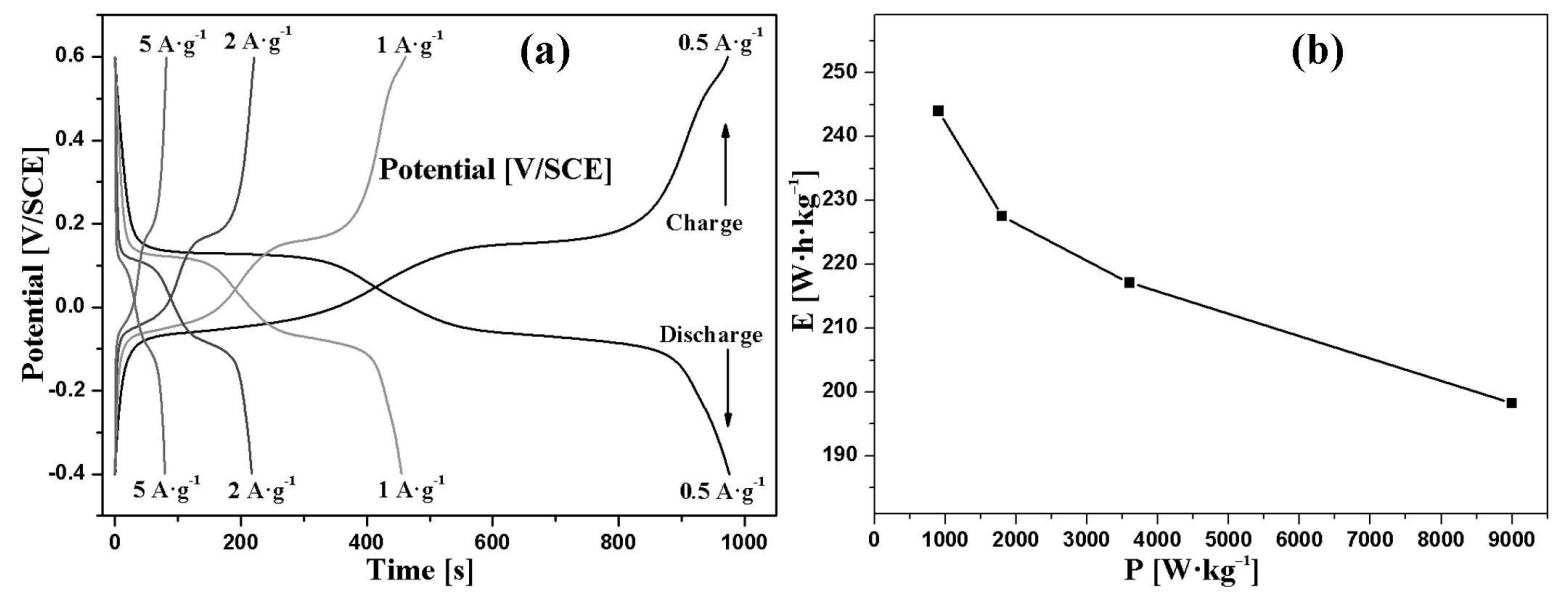

Fig. 7. (a) Galvanostatic charge and discharge curves at different current densities of HVOM; (b) Ragone plot of HVOM. 
Table 1. Comparison of specific capacitance of the $\mathrm{HVOM}$ with $\mathrm{V}_{2} \mathrm{O}_{5}$ materials reported in the previous literature.

\begin{tabular}{|c|c|c|c|c|}
\hline Types of $\mathrm{V}_{2} \mathrm{O}_{5}$ material & Electrolyte & $\begin{array}{c}\text { Potential range } \\
{[\mathrm{V}]}\end{array}$ & $\begin{array}{c}\text { Specific } \\
\text { capacitance }\left[\mathrm{F} \cdot \mathrm{g}^{-1}\right]\end{array}$ & Literature \\
\hline $\mathrm{V}_{2} \mathrm{O}_{5}$ nanoflowers, nanoballs, nanowires, nanorods & $1 \mathrm{~mol} \cdot \mathrm{dm}^{-3} \mathrm{Na}_{2} \mathrm{SO}_{4}$ & 0 to 1 & $119,161,177,235$ & [28] \\
\hline $\mathrm{V}_{2} \mathrm{O}_{5}$ nanobelts, nanoparticles, microspheres & $1 \mathrm{~mol} \cdot \mathrm{dm}^{-3} \mathrm{LiNO}_{3}$ & -0.4 to 0.8 & $140,276,308$ & [3] \\
\hline Electrospun $\mathrm{V}_{2} \mathrm{O}_{5}$ nanofibers & $2 \mathrm{~mol} \cdot \mathrm{dm}^{-3} \mathrm{KCl}$ & 0 to $0.9 \mathrm{~V}$ & 190 & {$[26]$} \\
\hline Electrospun $\mathrm{V}_{2} \mathrm{O}_{5}$ nanofibers & $1 \mathrm{~mol} \cdot \mathrm{dm}^{-3} \mathrm{LiClO}_{4}$ in $\mathrm{PC}$ & 0 to 3 & 250 & {$[26]$} \\
\hline Nano porous $\mathrm{V}_{2} \mathrm{O}_{5}$ & $2 \mathrm{~mol} \cdot \mathrm{dm}^{-3} \mathrm{KCl}$ & -0.2 to 0.8 & 214 & [38] \\
\hline $\mathrm{V}_{2} \mathrm{O}_{5}$ powders & $2 \mathrm{~mol} \cdot \mathrm{dm}^{-3} \mathrm{KCl}$ & -0.2 to 0.7 & 262 & [39] \\
\hline Interconnected $\mathrm{V}_{2} \mathrm{O}_{5}$ nanoporous network & $0.5 \mathrm{~mol} \cdot \mathrm{dm}^{-3} \mathrm{~K}_{2} \mathrm{SO}_{4}$ & 0.2 to $0.8 \mathrm{~V}$ & 304 & [27] \\
\hline $\mathrm{V}_{2} \mathrm{O}_{5}$ nanowires & $1 \mathrm{~mol} \cdot \mathrm{dm}^{-3} \mathrm{LiNO}_{3}$ & -0.4 to 0.8 & 351 & [24] \\
\hline Hollow spherical $\mathrm{V}_{2} \mathrm{O}_{5}$ & $5 \mathrm{~mol} \cdot \mathrm{dm}^{-3} \mathrm{LiNO}_{3}$ & -0.2 to 0.8 & 479 & [22] \\
\hline$\beta-\mathrm{V}_{2} \mathrm{O}_{5}$ thin films & $1 \mathrm{~mol} \cdot \mathrm{dm}^{-3} \mathrm{LiClO}_{4}$ in $\mathrm{PC}$ & -0.8 to 1.2 & 346 & [40] \\
\hline Hollow $\mathrm{V}_{2} \mathrm{O}_{5}$ microspheres & $1 \mathrm{~mol} \cdot \mathrm{dm}^{-3} \mathrm{LiNO}_{3}$ & -0.4 to 0.6 & 488 & This work \\
\hline
\end{tabular}

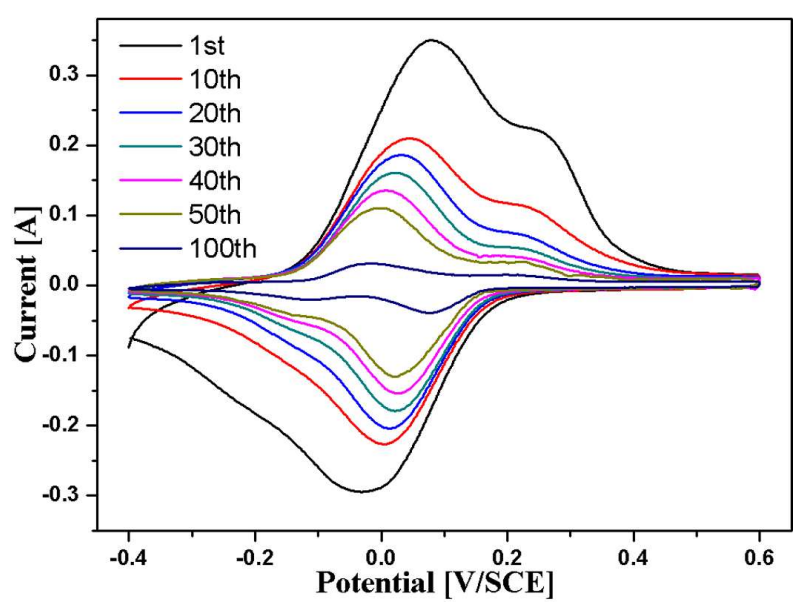

Fig. 8. Cycling behavior of HVOM recorded by $\mathrm{CV}$ at $20 \mathrm{mV} \cdot \mathrm{s}^{-1}$ scan rate.

the change and discharge of the specific capacitance. A high initial specific capacitance of $455 \mathrm{~F} \cdot \mathrm{g}^{-1}$ was achieved. The specific capacitance after 10, 30, 50, 100 cycles was $314 \mathrm{~F} \cdot \mathrm{g}^{-1}$, $170 \mathrm{~F} \cdot \mathrm{g}^{-1}, 103 \mathrm{~F} \cdot \mathrm{g}^{-1}, 33 \mathrm{~F} \cdot \mathrm{g}^{-1}$ which means that $69.0 \%, 37.4 \%, 22.6 \%, 7.3 \%$ of its initial capacitance was remained (Fig. 9b). The results intuitively reveal that the specific capacitance of HVOM quickly fades over 100 cycles. The reason is related with phase conversion and dissolution of HVOM. The redox peaks in the $100^{\text {th }}$ cycle shown in Fig. 8 can be obviously detected in the CV curves. Fig. 9a displays the characteristic plateaus which exist at almost identical potential during the whole cycling process. The above results indicate that the phase transition is completely reversible with increasing the numbers of cycles. Thus, the phase transformation of HVOM cannot be the reason for the fast fading of specific capacitance. The reason may be the dissolution of electrode material because the electrolyte solution gradually turns yellow during the constant charge/discharge process, which is a common phenomenon for vanadium oxides used as electrodes for Li-ion batteries and SCs [3, 4, 41]. Moreover, the strong stress introduced by the structure expansion during $\mathrm{Li}^{-}$ ion insertion into HVOM may easily cause the structure to collapse which promotes dissolution. The coulombic efficiency is almost $100 \%$ as depicted in Fig. 9b, which suggests using HVOM as the SCs electrode with high efficiency. This result also supports the view that the dissolution of electrode material of HVOM is the reason for the fast fading of specific capacitance. To further improve cycling stability, we may choose a suitable electrolyte or coat a conductive polymer layer on their surface [42].

\section{Conclusions}

Hollow $\mathrm{V}_{2} \mathrm{O}_{5}$ microspheres with rough surface constructed from nanoparticles were synthesized by a template solvothermal approach and subsequent calcination. The samples were characterized by FE-SEM, XRD, IR, BET, CV and GCD. Hollow $\mathrm{V}_{2} \mathrm{O}_{5}$ microspheres displayed excellent pseudocapacitance property and their 

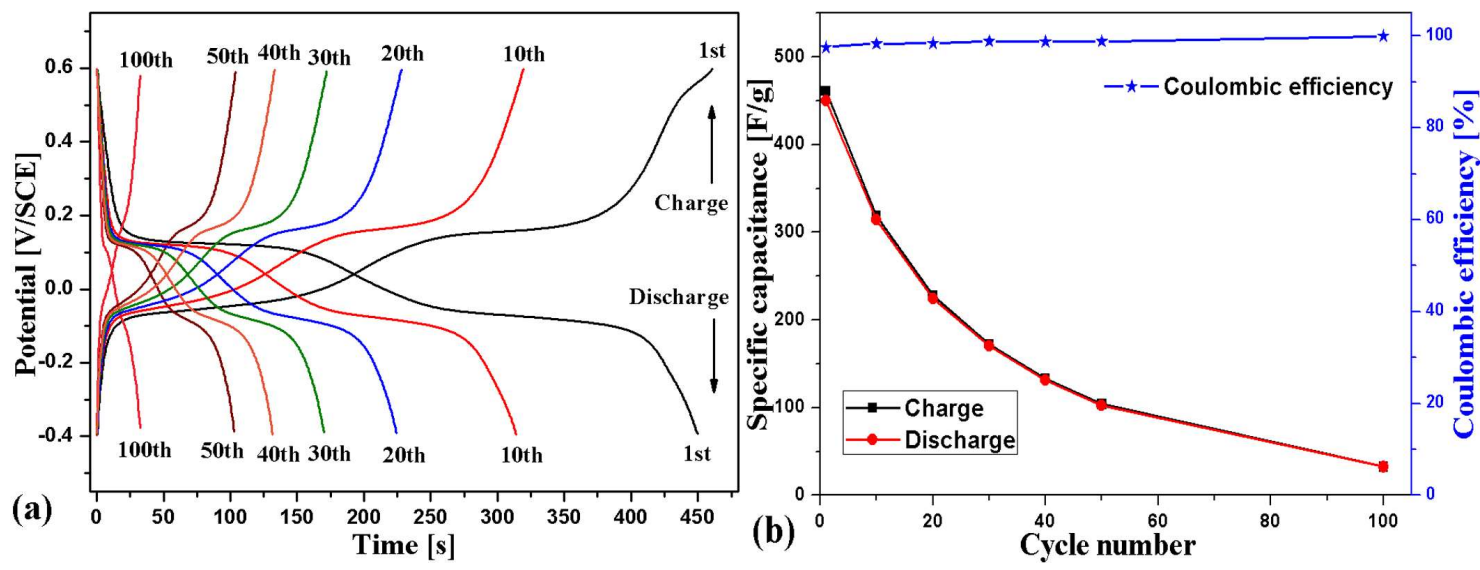

Fig. 9. Cycling behavior of HVOM recorded at a current density of $1 \mathrm{~A} \cdot \mathrm{g}^{-1}$ by GCD: (a) galvanostatic charge and discharge curves; (b) cyclic stability of the specific capacitance.

specific capacitances were $488 \mathrm{~F} \cdot \mathrm{g}^{-1}, 455 \mathrm{~F} \cdot \mathrm{g}^{-1}$, $434 \mathrm{~F} \cdot \mathrm{g}^{-1}$ and $396 \mathrm{~F} \cdot \mathrm{g}^{-1}$ at the current density of $0.5 \mathrm{~A} \cdot \mathrm{g}^{-1}, 1 \mathrm{~A} \cdot \mathrm{g}^{-1}, 2 \mathrm{~A} \cdot \mathrm{g}^{-1}$ and $5 \mathrm{~A} \cdot \mathrm{g}^{-1}$, respectively. They also exhibited an excellent energy density of $8.784 \times 10^{5} \mathrm{~J} \cdot \mathrm{kg}^{-1}$ at a power density of $900 \mathrm{~W} \cdot \mathrm{kg}^{-1}$. The good electrochemical properties of hollow $\mathrm{V}_{2} \mathrm{O}_{5}$ microspheres make them a promising candidate as a cathode material for SCs.

\section{Acknowledgements}

This work was partially supported by the National Natural Science Foundation of China (21601026, 21271037), the Fundamental Research Funds for the Central Universities (DUT16LK37) and the Science Research Project of Liaoning Province Education Department (L2015123).

\section{References}

[1] Winter M., Brodd R.J., Chem. Rev., 104 (2004), 4245.

[2] Yu Z., Tetard L., Zhai L., Thomas J., Energ. Environ. Sci., 8 (2015), 702.

[3] Zhang Y., Zheng J., ZhaO Y., Hu T., GaO Z., MENG C., Appl. Surf. Sci., 377 (2016), 385.

[4] Zhang Y., Zheng J., Hu T., Tian F., Meng C., Appl. Surf. Sci., 371 (2016), 189.

[5] Wu Y., Gao G., Wu G., J. Mater. Chem. A, 3 (2015), 1828.

[6] Zheng J., Zhang Y., WANG N., ZhaO Y., Tian F., MENG C., Mater. Lett., 171 (2016), 240.

[7] Zhang L.L., ZhaO X.S., Chem. Soc. Rev., 38 (2009), 2520.

[8] Zhang Y., Tan X., Meng C., Mater. Sci.-Poland, 33 (2015), 560.
[9] Zhang Y., Zhang J., Zhang X., Mo S., Wu W., NiU F., Zhong Y., LiU X., Huang C., LiU X., J. Alloy. Compd., 570 (2013), 104.

[10] Zhang Y., Wang N., HuAng Y., HuAng C., Mei X., Meng C., Mater. Sci.-Poland, 32 (2014), 236.

[11] Zhang Y., Liu X., Chen D., Yu L., Nie J., Yi S., Li H., Huang C., J. Alloy. Compd., 509 (2011), L69.

[12] Zhang Y., WANG N., HUANG Y., WU W., Huang C., Meng C., Ceram. Int., 40 (2014), 11393.

[13] Wei J., Ji H., Guo W., Nevidomskyy A.H., NATELSON D., Nat. Nanotechnol., 7 (2012), 357.

[14] Zhang Y., Meng C., Mater. Lett., 160 (2015), 404.

[15] Zhang Y., Mater. Sci.-Poland, 34 (2016), 169.

[16] Zhang Y., Huang C., Meng C., Hu T., Mater. Chem. Phys., 177 (2016), 543.

[17] Zhang Y., Huang Y., Mater. Lett., 182 (2016), 285.

[18] Zhang Y., Chen C., Wu W., NiU F., LiU X., Zhong Y., CaO Y., LiU X., Huang C., Ceram. Int., 39 (2013), 129.

[19] Zhang Y., Zhang J., Zhang X., Deng Y., Zhong Y., Huang C., LiU X., Liu X., Mo S., Ceram. Int., 39 (2013), 8363.

[20] Zhang Y., Zhang J., Zhang X., HuAng C., Zhong Y., Deng Y., Mater. Lett., 92 (2013), 61.

[21] Zhang Y., LiU X., Xie G., Yu L., Yi S., Hu M., HuANG C., Mater. Sci. Eng. B-Adv., 175 (2010), 164.

[22] Yang J., Lan T., LiU J., Song Y., Wei M., Electrochim. Acta, 105 (2013), 489.

[23] Zhu J., CaO L., Wu Y., Gong Y., LiU Z., Hoster H.E., Zhang Y., Zhang S., Yang S., YAN Q., AJAYAN P.M., VAJTAI R., Nano Lett., 13 (2013), 5408.

[24] Wang N., Zhang Y., Hu T., ZhaO Y., Meng C., Curr. Appl. Phys., 15 (2015), 493.

[25] Umeshbabu E., Ranga Rao G., J. Colloid Interf. Sci., 472 (2016), 210.

[26] Wee G., Soh H.Z., Cheah Y.L., Mhaisalkar S.G., SRInivasan M., J. Mater. Chem., 20 (2010), 6720 . 
[27] Saravanakumar B., Purushothaman K.K., MURALIDHARAN G., ACS Appl. Mater. Inter., 4 (2012), 4484.

[28] Mu J., Wang J., Hao J., Cao P., Zhao S., Zeng W., Miao B., Xu S., Ceram. Int., 41 (2015), 12626.

[29] Pan A., Wu H.B., Yu L., Lou X.W., Angew. Chem., Int. Edit., 52 (2013), 2226.

[30] Pan A.Q., Wu H.B., Zhang L., Lou X.W., Energ. Environ. Sci., 6 (2013), 1476.

[31] Su D.W., Dou S.X., Wang G.X., J. Mater. Chem. A, 2 (2014), 11185.

[32] Chen M., Xia X., Yuan J., Yin J., Chen Q., J. Power Sources, 288 (2015), 145.

[33] Sun X., Li Y., Angew. Chem. Int. Edit., 43 (2004), 597.

[34] Saravanakumar B., Purushothaman K.K., MURAlidHARAN G., J. Electroanal. Chem., 758 (2015), 111.

[35] Gilson T.R., Bizri O.F., Cheetham N., Dalton T., (1973) 291

[36] Delmas C., Cognac-Auradou H., Cocciantelli J.M., Menetrier M., Doumerc J.P., Solid State Ionics, 69 (1994), 257.
[37] QU Q.T., Shi Y., Li L.L., GuO W.L., WU Y.P., Zhang H.P., Guan S.Y., Holze R., Electrochem. Commun., 11 (2009), 1325.

[38] Reddy R.N., Reddy R.G., J. Power Sources, 156 (2006), 700.

[39] Lao Z.J., Konstantinov K., Tournaire Y., NG S.H., Wang G.X., LIU H.K., J. Power Sources, 162 (2006), 1451.

[40] Jeyalakshmi K., ViJayakumar S., NagaMUthu S., Muralidharan G., Mater. Res. Bull., 48 (2013), 760.

[41] Li H.-Y., Wei C., WANG L., ZuO Q.-S., Li X., XIE B., J. Mater. Chem. A, 3 (2015), 22892.

[42] Zhang Y., Fan M., LiU X., Huang C., Li H., Eur. J. Inorg. Chem., 2012 (2012), 1650.
Received 2016-05-31

Accepted 2016-12-14 